\title{
ANALISA PEMANTAUAN PERKEMBANGAN PEKERJAAN SURVEI TOPOGRAFI SEISMIK PT PERTAMINA EP SECARA ONLINE MENGGUNAKAN OPERATION DASHBOARD
}

\author{
Teguh Hariyanto ${ }^{1}$, Cherie Bhekti Pribadi ${ }^{2}$, Rino Harmasdiyono ${ }^{3}$ \\ 1,2,3 Departemen Teknik Geomatika, FTSLK-ITS, Kampus ITS Sukolilo, Surabaya, 60111, Indonesia \\ e-mail: ${ }^{1}$ tgh_hary@yahoo.com, ${ }^{2}$ cheriebhekti@gmail.com, ${ }^{3}$ harmasdiyono.rino@gmail.com
}

\begin{abstract}
Abstrak
PT Pertamina EP adalah perusahaan yang menyelenggarakan kegiatan usaha di sektor hulu bidang minyak dan gas bumi, meliputi eksplorasi dan eksploitasi. Survei seismik adalah tahapan awal dalam pencarian minyak dan gas di bawah permukaan bumi. Tahapan pelaksanaan survei seismik meliputi pekerjaan topografi (pengukuran lintasan, rintis, dan bridging), pemboran (drilling) dengan pengisian bahan peledak (preloading), perekaman data (recording), dan pengolahan data seismik yang dilakukan di lokasi survei. Pemantauan kegiatan survei seismik dilakukan secara intensif dan efektif oleh PT Pertamina EP untuk mendapatkan kualitas data yang baik.

Pada penelitian ini, penulis mendokumentasikan inovasi mengenai pembuatan Operation Dashboard berbasis aplikasi WebGIS untuk monitoring aktivitas survei seismik PT Pertamina EP. Aplikasi tersebut dibangun secara enterprise menggunakan piranti lunak dari Esri untuk menampilkan informasi spasial kepada pengguna. Data yang bersifat dinamis juga dapat diimplementasikan menggunakan tools update hosted layer to ArcGIS Online

Hasil dari penelitian ini adalah aplikasi WebGIS yang dapat diakses oleh user secara real time dan komunikatif dalam bentuk Operation Dashboard. Total pekerjaan kemajuan pengawasan topografi survei seismik pada bulan April 2017 (4 bulan pengerjaan lapangan) adalah selesai 23\%. Dengan penggunaan aplikasi Operation Dashboard, progress monitoring survei seismik dapat dilakukan secara efisien, keamanan data terjaga, dan kualitas akuisisi data seismik dilapangan khususnya data topografi dapat diperoleh sesuai standar yang berlaku di PT Pertamina EP.
\end{abstract}

Kata Kunci: Monitoring, ArcGIS Online, Operation Dashboard.

\begin{abstract}
PT Pertamina EP is a company that carries out business activities in the oil and gas upstream sector, including exploration and exploitation. Seismic survey is the initial stage in the search for oil and gas below the earth's surface. Stages of conducting seismic surveys include topographic work (track measurement, pioneering, and bridging), drilling with preloading, recording, and seismic data processing carried out at the survey location. PT Pertamina EP has conducted intensive and effective monitoring of seismic survey activities to obtain good quality data.

In this study, the authors document innovations regarding the creation of a WebGIS-based Operation Dashboard for monitoring PT Pertamina EP's seismic survey activities. The application is built on an enterprise basis using software from Esri to display spatial information to users. Dynamic data can also be implemented using the hosted layer to ArcGIS Online update tool

The results of this study are WebGIS applications that can be accessed by users in real time and communicatively in the form of Operation Dashboard. Total work on topography seismic survey monitoring progress in April 2017 (4 months of fieldwork) was completed 23\%. With the use of the Operation Dashboard application, seismic survey progress monitoring can be done efficiently, data security is maintained, and the quality of seismic data acquisition in the field, especially topographic data can be obtained according to the applicable standards at PT Pertamina EP.
\end{abstract}

Keywords: Monitoring, ArcGIS Online, Operation Dashboard. 


\section{PENDAHULUAN}

Survei seismik merupakan sebuah metode investigasi struktur bawah tanah, terutama yang berkaitan dengan minyak, gas, dan cadangan mineral (Rafferty 2009). Survei seismik merupakan bagian vital dalam eksplorasi minyak dan gas bumi dengan cara memvisualisasikan susunan batuan di bawah permukaan tanah menggunakan gelombang seismik. Minyak dan gas bumi yang didapat untuk kebutuhan rumah tangga dan industri di Indonesia. Salah satu Perusahan Badan Usaha Milik Negara (BUMN) yang bergerak dalam bidang eksplorasi minyak dan gas bumi PT Pertamina Eksplorasi Produksi (EP) yang merupakan anak perusahaan dari PT Pertamina (Persero). Dalam perencanaan survei seismik, PT Pertamina EP melakukan survei pendahuluan untuk mengetahui kondisi lapangan dan rencana jalur lintasan yang akan dipasang peralatan seismik. Pada tahap ini perlu adanya sistem pencatatan dan pelaporan yang efektif untuk mempermudah pengawasan kinerja survei seismik yang akan dilakukan oleh PT Pertamina EP.

Proses pengawasan survei seismik dimulai dari input data, pengolahan, dan representasi dalam bentuk peta menggunakan konsep Sistem Informasi Geografis (Anam 2012). Ketiga hal tersebut mengimplementasikan analisa spasial agar data yang disajikan sesuai dengan kondisi di lapangan. Dengan memanfaatkan tools pada ArcGIS Online enterprise milik Esri, semua data survei seismik yang dilakukan oleh PT Pertamina EP dapat terintegrasi dengan baik dan akurat. Aplikasi berbasis web ini menerapkan enterprise database untuk menangani data lapangan yang kompleks. Melalui pembuatan skema geodatabase, semua data yang bersifat dinamis dapat terorganisir dengan baik. Penggunaaan karakteristik enterprise geo-database mempermudah pemasukan, pengolahan, dan penampilan data untuk diintegrasikan dengan Operation Dashboard (Esri 2017). Hasil produk yang diharapkan adalah analisa spasial secara informatif dan benar.

Maka dari itu sebagai sarana untuk mempresentasikan penggabungan semua data topografi survei seismik dari berbagai macam referensi dan dalam kurun waktu yang berbeda dapat digunakan Operation Dashboard for ArcGIS berbasis web. Dashboard menjadi rujukan peningkatan mutu kebutuhan bisnis di lingkup tertentu (Hariyanti 2008). Sehingga progress monitoring survei topografi seismik 2D Selingsing dapat dilaporkan secara real time, lengkap, dan interaktif.

Adapun rumusan masalah yang akan dibahas pada penelitian ini, yaitu:

a. Bagaimana mengintegrasikan dan mengolah data topografi survei seismik yang bersifat dinamis dalam melihat progress monitoring dari survei topografi seismik dapat tercapai?

b. Bagaimana informasi pada aplikasi Operation Dashboard untuk progress monitoring pekerjaan survei topografi survei seismik dapat disampaikan secara informatif?

Batasan masalah dari penelitian ini antara lain:

a. Wilayah yang menjadi daerah penelitian adalah pekerjaan survei topografi seismik 2D Selingsing tahun 2016-2017 di Kabupaten Pali dan Musi Banyuasin Provinsi Sumatera Selatan.

b. Pembuatan Operation Dashboard tentang progress pekerjaan survei topografi seismik 2D Selingsing PT Pertamina EP tahun 2016-2017.

c. Menggunakan enterprise login milik PT Pertamina EP pada akun ArcGIS Online.

d. Tidak mengarah pada analisa realisasi biaya yang dikeluarkan untuk data ganti rugi dan operasional pengerjaan survei topografi seismik 2D Selingsing PT Pertamina EP tahun 2016-2017.

Tujuan dari penelitian ini adalah sebagai berikut:

a. Mengintegrasikan data dan pengolahan data topografi survei seismik menjadi online editor untuk pelaporan yang efektif dalam

a. melihat monitoring progress dari topografi survei seismik.

b. Menganalisa monitoring progress pekerjaan topografi survei seismik pada aplikasi Operation Dashboard secara informatif.

\section{METODOLOGI PENELITIAN}

\section{Lokasi Penelitian}

Lokasi penelitian adalah di Kabupaten Pali dan Musi Banyuasin Provinsi Sumatera Selatan. Dengan koordinat pusat Kabupaten Pali 3॰14'23,35" LS dan 104.0'26,05" BT serta koordinat pusat Kabupaten Musi Banyuasin 2³2'39.13" LS dan 1034' $44.10^{\circ}$ BT dengan batas wilayah, yaitu:

Utara: Kab. Sarolangun, Kab. Batanghari, dan Kab. Muarojambi Prov. Jambi

Timur: Kab. Banyuasin 
Selatan: Kab. Musirawas

Barat: Kab. Panukal Abab Lematang Ilir

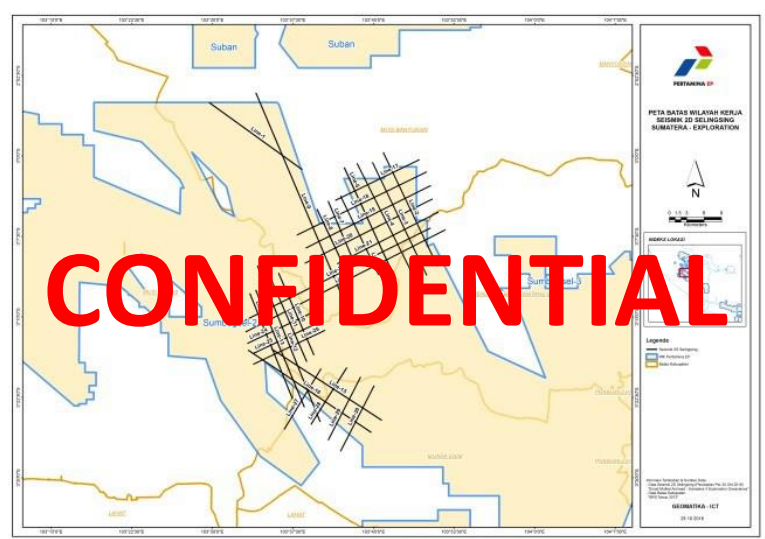

Gambar 1. Lokasi Penelitian (Arsip PT Pertamina EP, 2017)

\section{Data dan Peralatan}

Data yang digunakan dalam penelitian ini adalah:

a. Data koordinat survei topografi seismik 2D Selingsing tahun 2016-2017.

b. Peta Batas Wilayah Kerja Seismik 2D Selingsing Sumatera PT Pertamina EP Tahun 2017.

c. Data pengukuran survei seismik 2D Selingsing tahun 2016-2017.

d. Data tematik perencanaan survei seismik 2D Selingsing tahun 2016-2017 seperti Peta Geologi, Peta Rupa Bumi, Peta Aksesbilitas, data kehutanan, dan Peta Tata Guna Lahan.

e. Data Damage Assesment berupa data kepemilikan lahan yang dipakai untuk proses drilling dan recording di lapangan.

Sedangkan peralatan yang digunakan dalam penelitian ini adalah:
a. ArcGIS Desktop 10.4
b. XTOOLS PRO 16
c. ArcGIS Online
d. Operation Dashboard
e. Microsoft Office Word
f. Microsoft Office Excel

\section{Pengolahan Data}

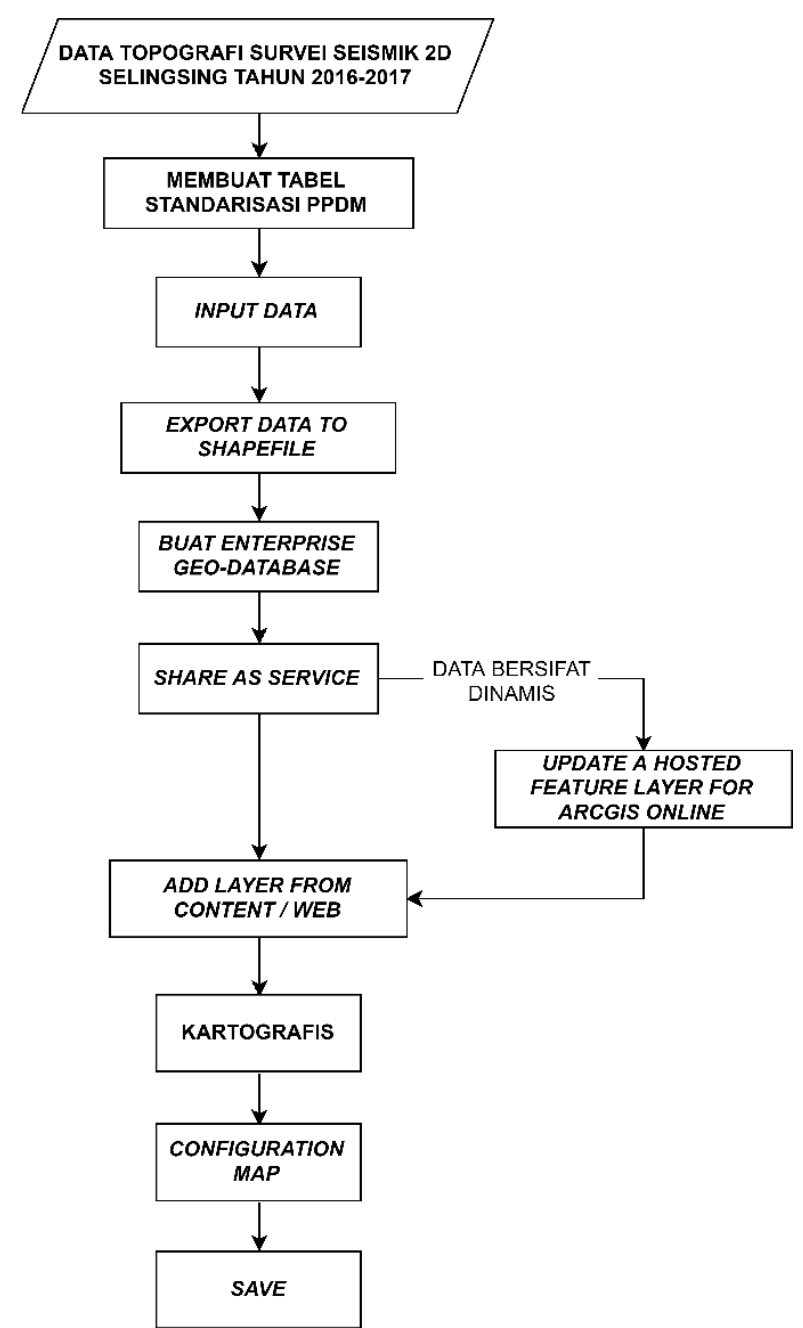

Gambar 2. Diagram Alir Pengolahan Data

\section{HASIL DAN PEMBAHASAN}

\section{Analisa Overview Feature Service ArcGIS Online}

Dalam overview yang ditunjukkan dalam Gambar 3 terdapat judul feature layer yaitu 2D SELINGSING FINAL dengan definisinya merupakan pekerjaan pengawasan kemajuan topografi survei seismik. Terdapat juga informasi tanggal dibuat agar dapat diinformasikan perancangan sistem pelaporan ini mulai dikerjakan dan menjadi bahan evaluasi ketepatan akusisi data yang diambil. Dalam penelitian ini mulai dibangun sistemnya pada tanggal 12 April 2018 dan diperbarui tanggal 13 April 2018. Deskripsi data berisikan tahun akuisisi data yaitu 2016-2017. 


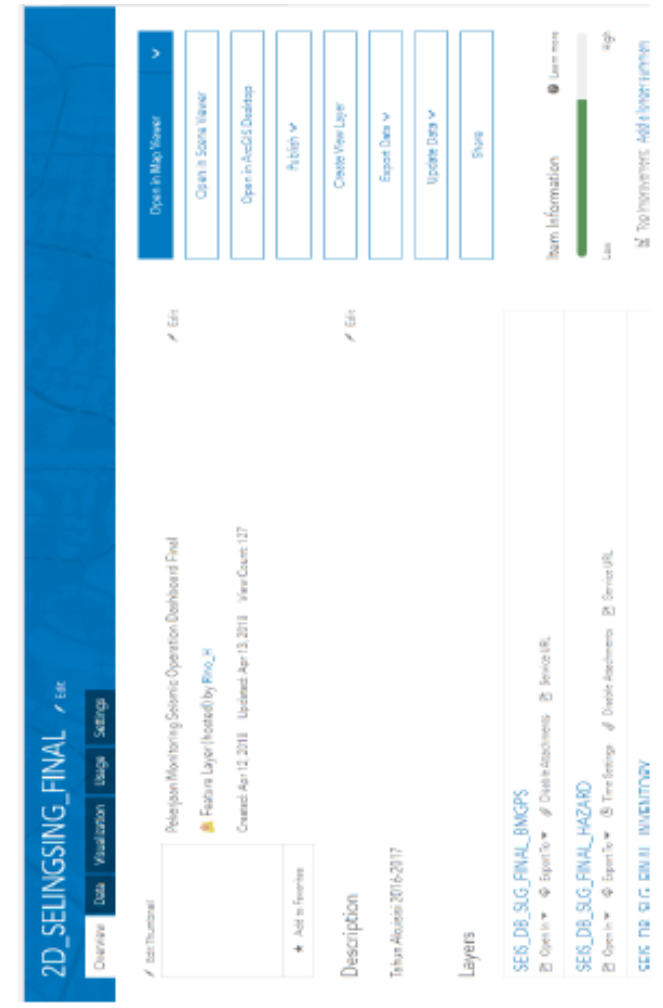

Gambar 3. Overview Feature Service pada ArcGIS Online

\section{Analisa Update Hosted Feature ArcGIS Online}

Dalam kondisi data yang bersifat dinamis, maka data spasial dan atribut dalam komputer lokal harus bisa diperbarui secara otomatis ke dalam ArcGIS Online. Penambahan yang dilakukan harus memiliki kesamaan skema dan karakteristik berdasarkan geo-database sebelumnya. Data yang ditambahkan juga dipastikan memiliki entitas ID Global. Sebagai contoh, seperti yang ditunjukkan pada Gambar 4 fitur BM GPS berisi sebanyak 36 data. Dalam melakukan pekerjaan dimisalkan mendapat penambahan 3 data baru yang telah sesuai dengan geo-database lamanya. Penambahan data menghasilkan total 39 data BM GPS ditunjukkan pada gambar 5 yang terbarui secara otomatis ke dalam ArcGIS Online.

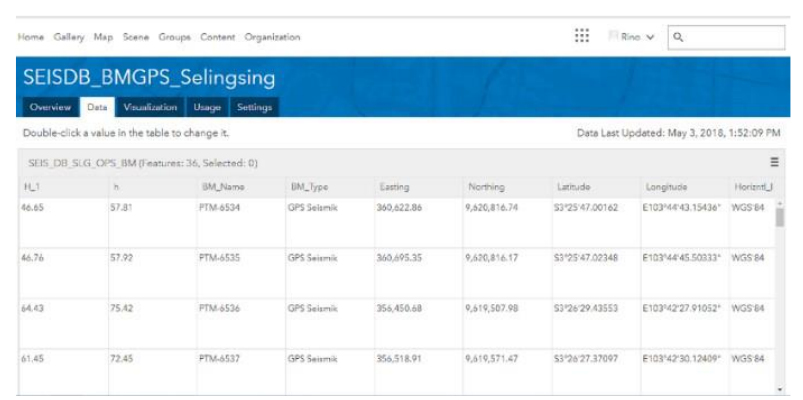

Gambar 4. Feature BM GPS sebanyak 36 data

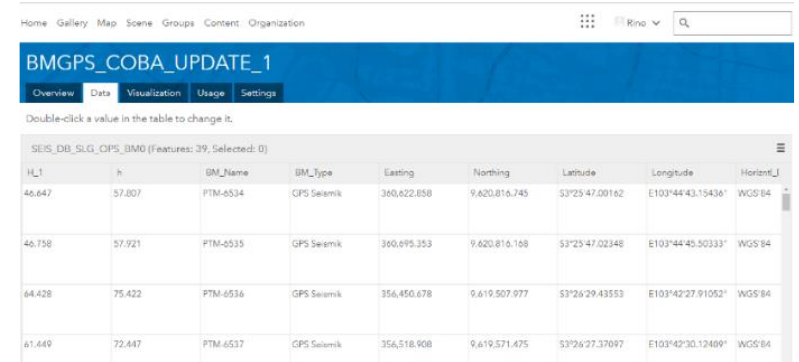

Gambar 5. Feature BM GPS sebanyak 39 data yang sudah diperbarui

\section{Analisa Operation Dashboard}

Kemajuan pekerjaan penentuan titik shootpoint dan trace telah selesai $100 \%$ menggunakan metode stake out dengan tanggal akuisisi data 20 November 2016 hingga 26 Maret 2017. Dalam pelaporan kemajuan keseluruhan pekerjaan topografi survei seismik telah terlaksana 23\% dalam rentang waktu Desember 2016 hingga April 2017, dengan rincian proses pendataan ganti rugi (inventori) sebesar 30,3\% ; kemajuan pekerjaan drilling sebesar $26,7 \%$ sepanjang Desember 2016 hingga April 2017 ; kemajuan pekerjaan perekaman survei seismik sebesar $12,1 \%$ sepanjang Januari hingga Februari 2017.

Dari pengolahan pada Operation Dashboard perlu dibandingkan dengan pelaporan konvensional yang melakukan perhitungan pada data tabular. Berikut perbandingannya :

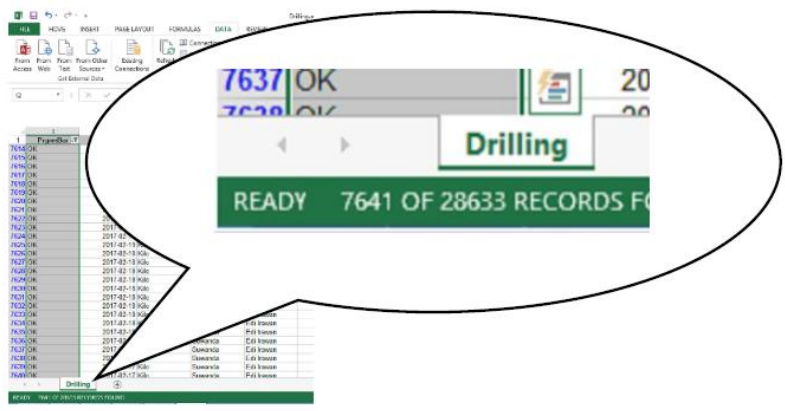

Gambar 6. Data Tabular Kemajuan Pekerjaan Drilling

Pada Gambar 6 terhitung sebanyak 7.641 titik dari 28.632 titik sudah terselesaikan proses drillingnya $(7.641 / 28.632=26,7 \%)$ yang artinya sesuai dengan apa yang ditampilkan pada Operation Dashboard.

Pada Gambar 8 terhitung sebanyak 3.475 titik dari 28.632 titik sudah terselesaikan proses recordingnya $(3.475 / 28.632=12,1 \%)$ yang artinya sesuai dengan apa yang ditampilkan pada Operation Dashboard. 


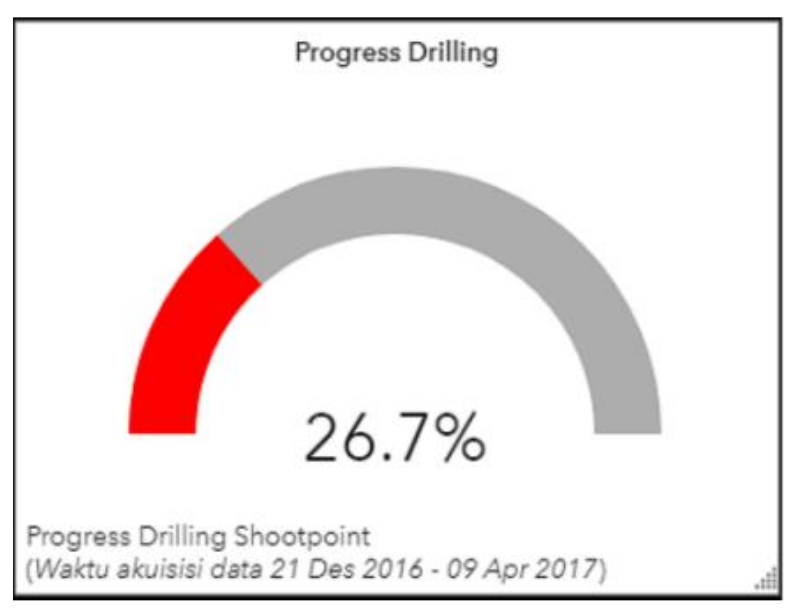

Gambar 7. Presentase Kemajuan Pekerjaan Drilling

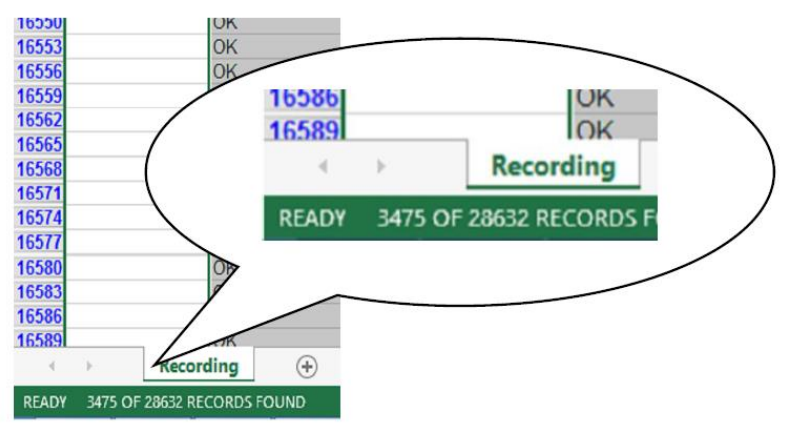

Gambar 8. Data Tabular Kemajuan Recording

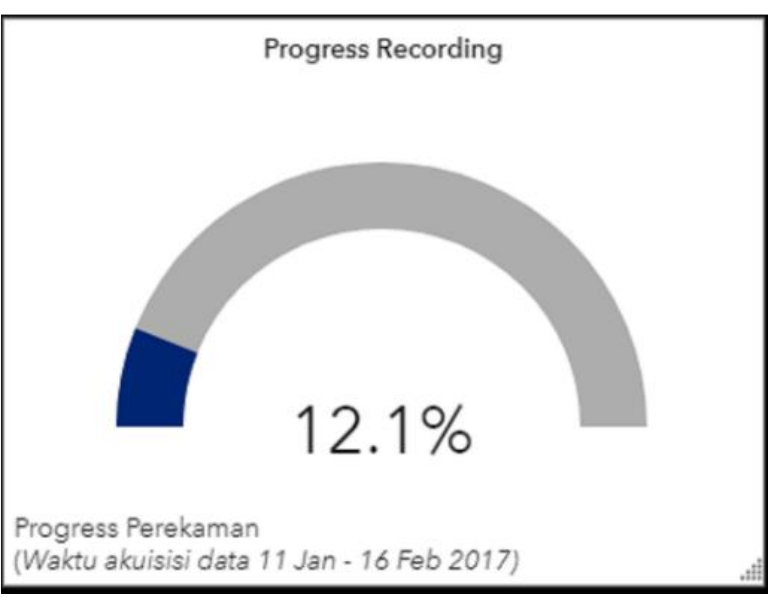

Gambar 9. Presentase Kemajuan Pekerjaan Recording

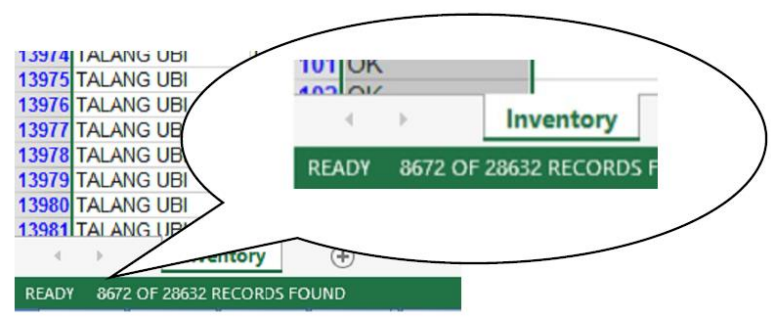

Gambar 10. Data Tabular Kemajuan Pencatatan Inventarisasi

Pada Gambar 10 terhitung sebanyak 8.672 titik dari 28.632 titik sudah terselesaikan proses inventarisasinya ( $8.67228 .632=30,3 \%$ ) yang artinya sesuai dengan apa yang ditampilkan pada Operation Dashboard.

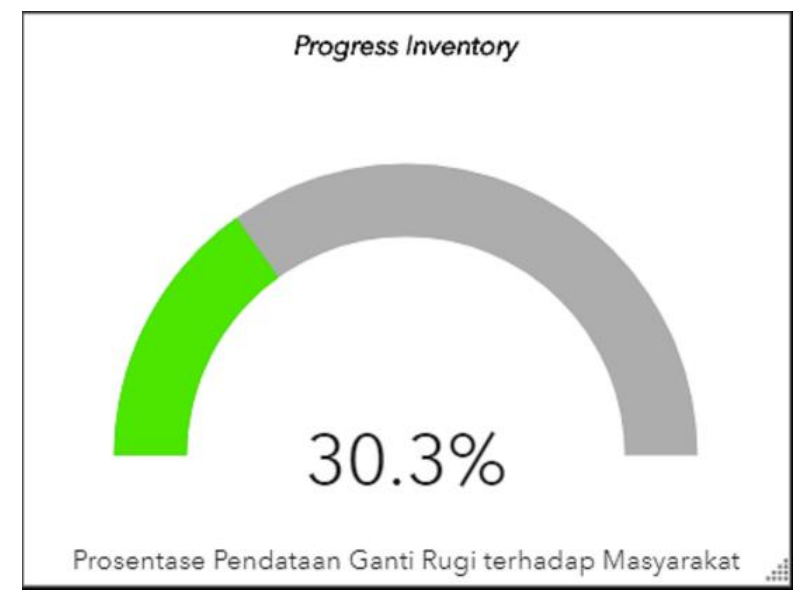

Gambar 11. Presentase Kemajuan Pekerjaan Pencatatan Inventarisasi

\section{KESIMPULAN}

Dari hasil pengembangan Operation Dashboard untuk mengawasi kemajuan pekerjaan hasil topografi survei seismik di Pertamina EP menggunakan ArcGIS Online dengan enterprise milik Esri, dapat disimpulkan bahwa:

a. Entitas pada Tabel Standarisasi Professional Petroleum Data Management (PPDM) sudah standar dan dapat digunakan secara jangka panjang untuk menampilkan pelaporan yang informatif di setiap atributnya. Dengan begitu pengembangan sistem dapat diimplementasikan ketika data yang digunakan bersifat dinamis. Data dapat ditambahkan melalui komputer lokal dengan format dan skema geodatabase yang sama sebelumnya menggunakan Update Hosted Layer untuk ArcGIS Online.

b. Operation Dashboard dapat berjalan sesuai dengan data yang tersedia, dilaporkan secara komunikatif, dan dapat dipertanggungjawabkan. Operation Dashboard memiliki kemudahan dalam membuat chart dan diagram sehingga pelaporan dengan cepat dimengerti oleh users dalam bentuk laporan presentase angka. Berbeda dengan penggunaan tabular excel yang rumit dalam pembuatan hingga maksud dan tujuannya untuk pelaporan progress. Pembuatan Seismic Operation Dashboard memberikan eksistensi divisi Geomatika dalam pekerjaan survei seismik melalui analisa ketelitian dan pelaporan pekerjaan topografi Survei Seismik di PT Pertamina EP. Total pekerjaan kemajuan 
pengawasan topografi survei seismik pada bulan April 2017 (4 bulan pengerjaan lapangan) adalah selesai $23 \%$. Sehingga merekomendasikan kepada tim geologi dan tim support lainnya di lapangan untuk segera menyelesaikan dengan tepat waktu. Hal tersebut juga dapat dijadikan dasaran untuk penambahan strategi survei yang efektif.

\section{UCAPAN TERIMA KASIH}

Penulis R. H. mengucapkan terima kasih kepada PT Pertamina EP yang telah memberikan pembelajaran, dukungan, dan bantuan berupa data-data yang dibutuhkan dalam penelitian ini sehingga dapat berjalan dengan lancar.

\section{DAFTAR PUSTAKA}

Anam, S. 2012. Peranan Geodesi Geomatika dalam Industri Migas dan Permasalahannya. Jakarta: MDGTI PT Pertamina EP.

Esri. 2017. Operation Dashboard for ArcGIS. <URL: http://doc.arcgis.com/en/operationsdashboard/windows-desktop/author/create-amap.htm>. Dikunjungi pada tanggal 4 Oktober 2017, jam 09.00 WIB.

Hariyanti, E., Endah, P. 2014. "Perancangan Sistem Dashboard untuk Monitoring Indikator Kinerja Universitas". (SESINDO 2014), 2.

Rafferty, J. P. 2009. Seismic Survey. $<$ URL:https://www.britannica.com/science/seism ic-survey\#Article-History>. Dikunjungi pada tanggal 1 Oktober 2017, jam 20.00 WIB. 